\title{
COVID-19 Pandemic, Part I: What to Do and Who to Blame? Susceptibility to Viral Infection via Jeopardized Immunity
}

\author{
Ilia Brondz $\mathbb{B}$ \\ Norwegian Drug Control and Drug Discovery Institute (NDCDDI) AS, Ski, Norway \\ Email: ilia.brondz@gmail.com
}

How to cite this paper: Brondz, I. (2020) COVID-19 Pandemic, Part I: What to Do and Who to Blame? Susceptibility to Viral Infection via Jeopardized Immunity. International Journal of Analytical Mass Spectrometry and Chromatography, 8, 7-13. https://doi.org/10.4236/ijamsc.2020.82002

Received: May 14, 2020

Accepted: June 27, 2020

Published: June 30, 2020

Copyright $\odot 2020$ by author(s) and Scientific Research Publishing Inc. This work is licensed under the Creative Commons Attribution International License (CC BY 4.0).

http://creativecommons.org/licenses/by/4.0/

\begin{abstract}
When this tragedy ends, it will become clear whether it is a pandemic, epidemic, mass infection, or mass psychosis (initiated by mass media with heavy engagement from political and economic establishments). The USA and other countries are raining accusations upon China, and vice versa. This problem will have future impacts on human society and civilization will be quite different following the "Pandemic of COVID-19". Although this series of papers will discuss a broad array of related problems, the author contends that the most important priorities are developing medications against diseases and improving our scientific understanding of the social situations and substances that jeopardize human health and increase our susceptibility to viral infection. Later papers in this series will provide support for the Chinese claim that chloroquine may be a useful medication for patients with viral infection.
\end{abstract}

\section{Keywords}

Pandemic of COVID-19, Susceptibility to Viral Infection, Jeopardized Immunity

\section{Introduction}

Two actors are involved in disease: the virus and immunity to the virus. Healthy young individuals can successfully resist COVID-19 without infection, or with mild symptoms. However, older adults with preconditions and those with compromised immunity are easy targets for viral infection, with lethal outcomes. We now have a growing understanding of the factors that lead to this illness and morbidity, some of which will be presented herein. Possible treatment medications will be presented later in COVID-19 Pandemic, Part II. 


\section{Dogmatism Is a Harmful Approach}

Many scientific discussions have addressed the questions, "Is a virus a living or dead particle?" and "Are viruses useful or harmful to humans and nature?" Without a clear understanding of these fundamental issues, it is impossible to understand whether we should eliminate viral infections and particles, or give them the freedom to have the effects for which they were designed... and whether, and to what extent, we should regulate their activities.

Materialism-based thinking denies that which cannot be explained by materialistic theory or encompassed within its dogma. There is a widespread perception that viral particles are not living, despite evidence of the composition and functions of a virion (i.e., a complete virus particle). $A$ virion is composed of (\%): $N, 14 \times 7 ; P, 0.49 ; S, 0.76 ; D N A, 3.2 ;$ total lipids, 5.0 (including cholesterol, 1.2; and phospholipid, 2.1); trace constituents of RNA, 0.1; carbohydrate, 0 - 2; $\mathrm{Cu}$, 0.02 ; flavin, $5 \times 10^{-4}$; and biotin, 1.3 [1]. A virus is a mobile genetic element. The fact that a virus is an intracellular parasite, which cannot reproduce itself outside the host cell, is neither a good nor strong enough argument to deny recognizing this particle as alive. Many simple microorganisms, like spirochetes, or treponemes, including Treponema pallida, are also strong intracellular parasites that cannot live or multiply outside cells. Evolutionarily, dependence of the parasite on a host organism leads to its simplified functions and composition, but this does not mean that a simplified parasite loses its status as a living organism. The same evolutionary simplification can also be seen in more complex organisms like parasitic (infectious) bacteria. A good example is the evolution of clause related bacteria in the family Pasteurellaceae, genus Actinobacillus and the family Pasteurellaceae, genus Haemophilus, species aphrophilus (Haemophilusaphrophilus was a species of Haemophilus but has recently been renamed Aggregatibacteraphrophilus). Clause related to HaemophilusaphrophiIus, the $A$. actinomycetemcomitans contains both $D$-glycero- $D$-mannoheptose and $L$-glycero- $D$-mannoheptose (7.8\% and $11.3 \%$, respectively) in its LPS (lipopolysaccharide), while $H$. aphrophilus contains only $L$-glycero- $D$-mannoheptose (17.4\%) [2]. During its evolution, $H$. aphrophilus lost $D$-glycero- $D$-mannoheptose by losing an array of enzymes that convert $L$-glycero- $D$-mannoheptose to $D$-glycero- $D$-mannoheptose, and some genetic material to synthesize these enzymes. Evidence for this loss has come from gas chromatography-mass spectrometry analyses [2] and [3] Figure 1.

It is unsurprising that during evolutionary history, organisms were rationalized, some becoming more complicated, others losing non-vital functions and organs, or having them become rudimentary. For example, the vulture, a scavenging bird of prey, has lost its head feathers and sharp leg claws. Other so-called higher organisms (e.g., humans) have lost function of organs such as the appendix. Viruses may have been the first organisms on Earth, and thus have the longest evolutionary history and pathway. Hence, they should be considered living. 

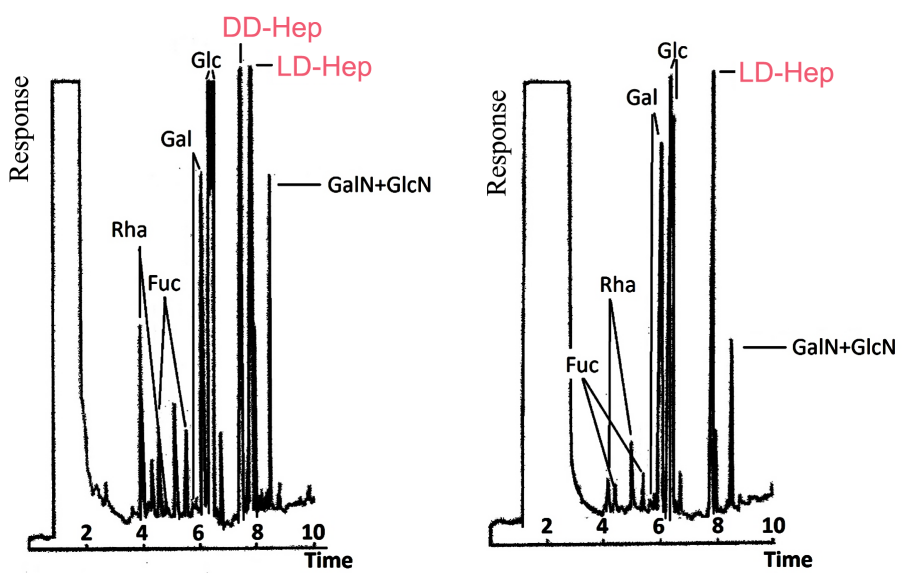

Figure 1. Gas chromatography-mass spectrometry (GCMS) analyses of lipopolysaccharide $H$. aphrophilus and $A$. actinomycetemcomitans. $D$-glycero- $D$-mannoheptose was detected exclusively in lipopolysaccharide from $A$. actinomycetemcomitans (left). GCMS of lipopolysaccharide from Haemophilus aphrophilus (right; figure from archive of Jupiter AS, Norway).

\section{Substances That Jeopardize Human Health and Expose Humans to Viral Infection versus Those That Increase Immunity}

There is a variety of substances and broadly administered pharmaceuticals that jeopardize human health, some of which are used day-to-day. It is essential to scrutinize these substances. It is well known that strong immunity protects us from bacterial, fungal, viral, and other diseases. Undermining society's broad-scale immunity exposes us all to infections, including viral infections. Anticancer medications are one example, although they are our only choice for saving patients' lives. However, many other medications are on the market exclusively to serve manufacturers' profits. These drugs cause allergic reactions and can be easily switched for other options. One example of this is Tuksior Tuksidrin, which is used in pediatric and adult antitussives. The main active pharmaceutical agent of Tuksi and Tuksidrin is pholcodine which includes its degraded products and other contaminants. "Florvaag et al. demonstrated [11] in a pilot study that pholcodine stimulates a dramatic increase of IgE in IgE-sensitized individuals. The quaternary amino function in pholcodine was implicated in the promotion of these reactions" [4]. "The latter had led to an elevated number of allergy and possible asthma cases in the Norwegian population relative to the population in neighboring Sweden" [5]. The individuals with asthma and allergy diseases are easy targets to pulmonary infections.

It is also worth noting that there are substances with the opposite properties that work as immunomodulators and increase immunity [6]-[11].

\section{Harmful Substances from Agricultural Use Jeopardize Human Immunity}

Immunity includes structural and humoral aspects, both of which are important 
for preventing infection. An important humoral contributor to immunity is lysozyme, which plays an important role in the prevention and eradication of bacterial and viral infections [12]. In the digestive system and other parts of organisms, lysozyme behaves differently than in laboratory glass (in vitro) under optimal $\mathrm{pH}$ and isotonic salinity. In laboratory glass, the 1,4-beta-linkages between $\mathrm{N}$-acetylmuramic acid and $\mathrm{N}$-acetyl- $D$-glucosamine (i.e., the major component of the gram-positive bacteria cell wall) were lysed. Previous work [13] has described a model of stomach conditions in which gal and taurine acids were changed to EDTA. Immune suppression is caused by some pesticides, including both acidic and salt formulas, which have been shown to partially deactivate immunity by suppressing lysozyme activity including: monochloroacetic acid (CAS number 79-11-8), dichloroacetic acid (CAS number 79-43-6), trichloroacetic acid (CAS number 76-03-9), and 2,2-dichloropropionic acid sodium salt (2,2-DCPANa, Dalapon) (CAS number 127-20-8) [13]. Such deactivation impacts the humoral part of the immune system by jeopardizing its defense ability, impacting the entire immune system, and making the organism more vulnerable to viral infections.

\section{Harm from Agricultural Fertilizers Like Pig Manure}

In recent years, under pressure from the green movement, agriculturalists have introduced pig manure fertilizer. Farmers usually collect and compost this material independently. No bacteriological or virologic control is performed before the product is administered to crop fields, which in European countries, are proximate to houses (Figure 2).

Some houses are less than $10 \mathrm{~m}$ from cultivated fields that have been fertilized with pig manure (Figure 3 ).

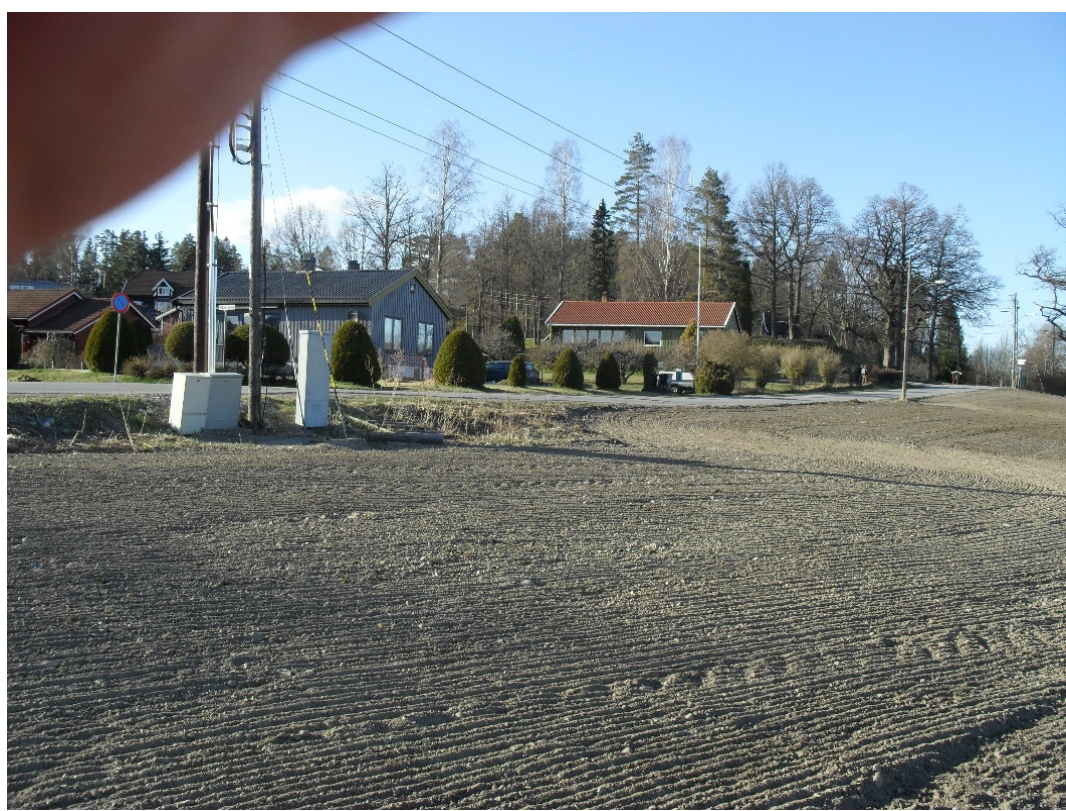

Figure 2. Norway's fields are proximate to houses in Ski settlement (author's photo). 


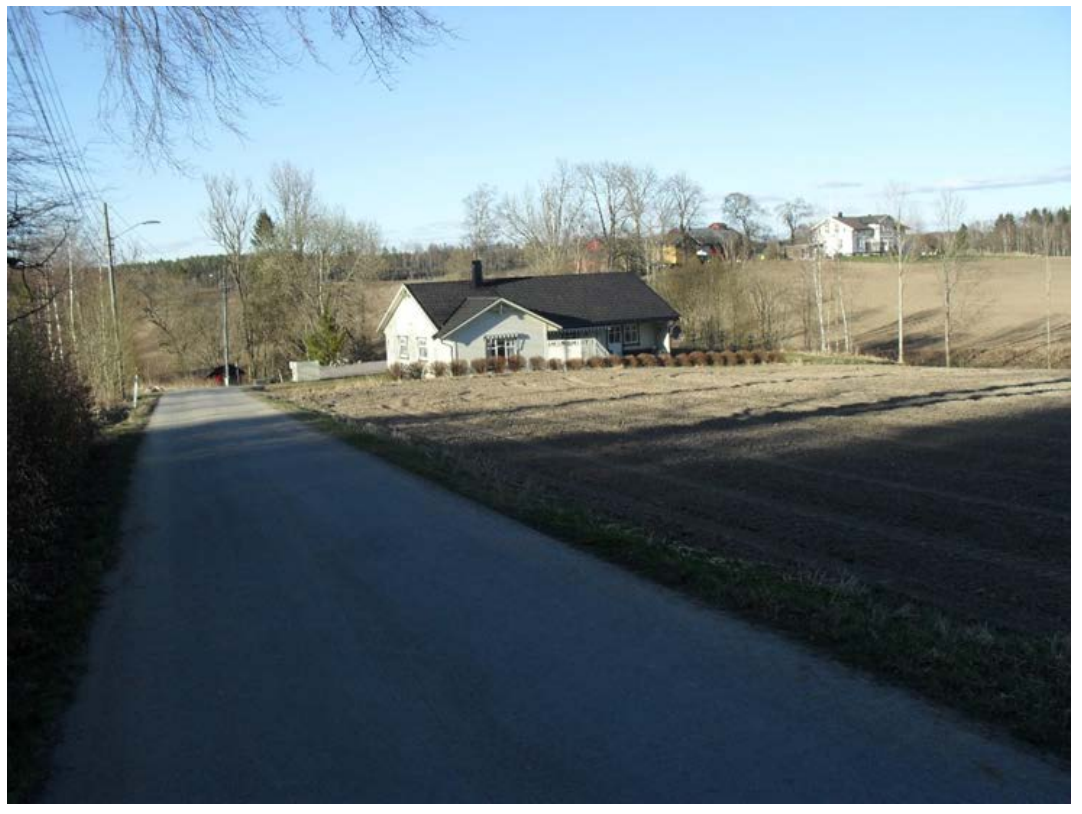

Figure 3. Norwegian house less than $10 \mathrm{~m}$ from a field fertilized with pig manure (author's photo).

Aggressive pressure by the green movement and the Green Party is clearly harmful to the population. Pigs can transmit many virulent bacteria and viruses from wild animals to humans and are host organisms for many infectious agents [14] that are common to both pigs and humans. They are also transitional and host organisms for a broad spectrum of coronaviruses.

Field fertilization with pig manure was introduced by some in the green movement. Thus, at present, all cereals, potatoes, vegetables, berries, etc. contain pig manure spores, both on the surface and/or incorporated in tissues, making them non-halal [14]. Further, pig manure droplets are present in ambient air during the spring and dust particles with adsorbed pig manure are present in the summer. All these are containing viral particles.

\section{Conclusion}

Medications with allergic potential and chemicals that can jeopardize the immune system must be restricted. Citizens must react strongly and resist pressure from the green movement. Crop field fertilization with pig manure must be forbidden.

\section{Acknowledgements}

The author thanks Jupiter AS, Norway for allowing me to use the chromatograms shown in Figure 1.

\section{Conflicts of Interest}

The author declares no conflicts of interest regarding the publication of this paper. 


\section{References}

[1] Zwartouw, H.T. (1964) The Chemical Composition of Vaccinia Virus. Journal of General Microbiology, 34, 115-123.

https://www.microbiologyresearch.org/docserver/fulltext/micro/34/1/mic-34-1-115. pdf? expires $=1603674554 \&$ id $=i d \& a c c n a m e=$ guest $\&$ checksum $=3$ A136DF7A55D12B2 218AC15CB8E653DE

[2] Brondz, I. and Olsen, I. (1989) Chemical Differences in Lipopolysaccharides from Actinobacillus (Haemophilus) Actinomycetemcomitans and Haemophilus aphrophilus: Clues to Differences in Periodontopathogenic Potential and Taxonomic Distinction. Infection and Immunity, 57, 3106-3109. https://doi.org/10.1128/IAI.57.10.3106-3109.1989

[3] Brondz, I. and Olsen, I. (1984) Differentiation between actinobacillus actinomycetemcomitans and haemophilus aphrophilus Based on Carbohydrates in Lipopolysaccharide, Journal of Chromatography B: Biomedical Sciences and Applications, 310, 261-272. https://doi.org/10.1016/0378-4347(84)80091-2

[4] Brondz, I. and Brondz, A. (2012) Supercritical Fluid Chromatography-Mass Spectrometry (SFC-MS) of Heterocyclic Compounds with Trivalent and Pentavalent Nitrogen in Cough Relief Medical Forms Tuxi and Cosylan. American Journal of Analytical Chemistry, 3, 870-876. https://doi.org/10.4236/ajac.2012.312A115

[5] Brondz, I. (2013) Mass Spectrometric Structure Elucidation of the Trivalent and Pentavalent Nitrogen Contaminants of Pholcodine in Cough Relief Medical Form Tuxidrin. International Journal of Analytical Mass Spectrometry and Chromatography, 1, 5-10. https://doi.org/10.4236/ijamsc.2013.11002

[6] Brondz, I. and Brondz, A. (2012) Recent Enhancement of the Immunity in Aids and Other Immunocompromised Patients by Hyperforin an Antibiotic from Hypericum perforatum L. (in Vitro Model) Part I. Journal of Biophysical Chemistry, 3, 304-310. https://doi.org/10.4236/jbpc.2012.34037

[7] Brondz, I. (2016) Super Antibiotics, Part I. Hyperforin. Voice of the Publisher, 2, 19-27. https://doi.org/10.4236/vp.2016.24004

[8] Brondz, I. (2016) Super Antibiotics, Part II. Hyperforin, Mass Spectroscopy (MS) and Gas Chromatography-Mass Spectrometry (GC-MS), Evidence of Permeability of the Blood-Testis Barrier (BTB) and the Blood-Brain Barrier (BBB) to Hyperforin. International Journal of Analytical Mass Spectrometry and Chromatography, 4, 66 -73. https://doi.org/10.4236/ijamsc.2016.44007

[9] Brondz, I. (2017) Super Antibiotics: Part III. Hyperforin, Revision of the Relative and Absolute Stereochemistry Presented by Bystrov et al. Voice of the Publisher, 3 , 15-24. https://doi.org/10.4236/vp.2017.32002

[10] Brondz, I. (2017) Super Antibiotics, Part IV. Hyperforin, Relative and Absolute Stereochemistry Elucidated by Gas-Chromatography Mass-Spectrometry with Supersonic Molecular Beams. International Journal of Analytical Mass Spectrometry and Chromatography, 5, 70-85. https://doi.org/10.4236/ijamsc.2017.53005

[11] Brondz, I. (2018) Super Antibiotics, Part VI: Hyperforin, Revision of Stereochemistry. Short Communications. International Journal of Analytical Mass Spectrometry and Chromatography, 6, 37-39. https://doi.org/10.4236/ijamsc.2018.62003

[12] Małaczewska, J., Kaczorek-Łukowska, E., Wójcik, R. and Siwicki, A. K. (2019). Antiviral Effects of Nisin, Lysozyme, Lactoferrin and Their Mixtures against Bovine Viral Diarrhoea Virus. BMC Veterinary Research, 15, Article No. 318. https://doi.org/10.1186/s12917-019-2067-6 
[13] Brondz, I. and Brondz, A. (2011) Suppression of Immunity by Some Pesticides, Xenobiotics, and Industrial Chemicals. In Vitro Model. Journal of Biophysical Chemistry, 2, 226-232. https://doi.org/10.4236/jbpc.2011.23028

[14] Brondz, I. (2018) Why Judaism and Islam Prohibit Eating Pork and Consuming Blood as a Food? Voice of the Publisher, 4, 22-31.

https://doi.org/10.4236/vp.2018.42003 